\title{
JUURNAL.RU
}

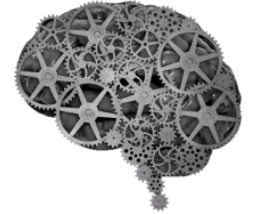

COMPANY GROUP "INTELLEKT"

Орлова Е.А. Белгородский государственный национальный исследовательский университет г. Белгород, Россия

doi: 10.18411/lj2016-5-3-14

\section{Структурный анализ неологизмов в политическом дискурсе английского языка}

Новые слова являются «символами» своего времени, спутниками развития общества. Современный мир характеризуется непрерывными изменениями в политической, экономической, социальной, научно-технической сферах. Появление новых реалий приводит к переосмыслению старых понятий и возникновению новой лексики, отражающей значимые явления, события и наше отношение к ним.

Жизнеспособность языка характеризуется в первую очередь особенностью безгранично пополняться новыми словами и значениями, которые образуются различными путями [1]. В связи с интенсивными изменениями на мировой политической арене, английский язык, имея статус международного, переживает «неологический взрыв». По данным Калифорнийской организации Global Language Monitor, словарный состав современного мирового языка пополняется новым словом каждые 98 минут. Таким образом, английский язык способен увеличиваться на десятки тысяч слов в год. Несмотря на то, что английский является языком-донором для многих ведущих языков мира, его развитие зависит в первую очередь от создания неологизмов за счет собственных ресурсов [1], а не от иностранных заимствований.

Благодаря современным технологиям, многие новообразования английского языка фиксируются электронными словарями, что упрощает их 
поиск и исследование. По последним сведениям «Английского неологического общества» (The English Neologia Society), в настоящий момент в Сети насчитывается более 75 электронных словарей неологизмов. Наибольшим авторитетом при анализе неологизмов обладают Unwords.com [3], Urban Dictionary [4], Word Spy [5], что и явилось ключевым моментом при выборе словарей для нашего исследования.

Огромный приток новых слов и необходимость их описания обусловили создание самостоятельной науки о неологизмах - неологии. Однако имея динамичное развитие в современном мире, данная дисциплина все еще не обзавелась емким однозначным определением термина «неологизм». Учитывая множество подходов к определению данного понятия, под неологизмами в данной работе мы будем понимать: лексические новообразования, заимствования, слова с расширенным значением.

Для появления неологизмов большую роль играют внутриязыковые факторы: тенденции к унификации, экономии, системности языковых средств, этимология, варьирование номинаций с различной внутренней формой, задачи экспрессивно-эмоциональной, стилистической выразительности [2].

Способов образования новых слов в системе современного английского языка довольно много [1], [2]: аффиксация, словосложение, конверсия, сокращение, обратное словообразование, сращение, постпозитивация, звукоподражание, повтор, чередование звуков, перенос ударения в слове, аббревиация, сочетание с заимствованной лексикой, переосмысление существующих значений. В рамках данной статьи мы ограничимся схематичным представлением структурного анализа наиболее популярных способов словообразования в рамках политической лексики. Примечателен тот факт, что для каждого из способов нам удалось найти неологизмы, включающие имена известных политических деятелей: Putinphile, Putin Law, medveput, Merkozy, Sarkozyed, Obama Bin Laden, Obama and Clinton, Barackholm Syndrome, bushama, Bushify, Saddaminem, Saddamists, Market-Leninism, Stalinoid, Hitlerbine Day, 
Napoleonophobia $и$ $\partial$.

Словосложение - это способ словообразования путем соединения двух (или более) слов в одно, которое пишется слитно или через дефис, а иногда раздельно: Putin-ize, Putin off, Obama bandwagon, obama-apologist, Merkel Effect, Loutspeaker, backfire effect, dirty tricks Thursday, blue state/red state/swing state, egocasting, headline risk, hyper-power, just-in-time politics, naked re-elect, Seabiscuit candidate, zombie lie $u$ дp. Словосложение является самым простым, а следовательно, самым продуктивным способом образования неологизмов.

Сокращение (усечение, инициальное сокращение и телескопия) - процесс уменьшения числа фонем и/или морфем у имеющихся в языке слов или словосочетаний без изменения их лексико-грамматического значения: Putinstinct $($ Putin + instinct), Barackobilia (Barack Obama + memorabilia), Obamabola (Obama + ebola), Eurogeddon (Europe + armageddon), Grexit (Greece or Greek + exit), infoganda (information + propaganda), lolbertarian (LOL (laugh out loud) + libertarian), oppo guy (opposition research + guy), pluto-populism (plutocrat + populism), shampaign (sham + campaign), hatriotism (hate + patriotism), Chindia (China + India), businesscrat (business + Democrat), condesplaining (condescending + explaining) democratatorship (democracy + dictatorship), genopolitics (genetics + politics) manufactroversy (manufactured + controversy) $u$ дp. Для толкования семантики различных видов сокращений необходимо обратиться к этимологии усечённых слов, образующих неологизм.

Суффиксация - образование новых слов путем добавления производных суффиксов к различным типам основ: Putinium, Putinism, Bushism, Obamabilia, Barackaholic, Baracknophobia, merkelicious, fauxtography, videocracy, dementocracy, ineptocracy, thictatorship, disgreenimation, gagreement, soapboxiomatic, frontrunneritis $u$ дp. Для неологизмов нашей тематической группы характерны суффиксы, обозначающие: состояние, процесс, результат, действие, абстрактное понятие, обобщенное явления, учение, принадлежность к философскому течению. Следует отметить, что примеров префиксации в нашем 
эмпирическом материале было зафиксировано недостаточное количество для их релевантного анализа.

Аббревиация - способ словообразования на базе сочетания слов или (реже) одного слова путем сокращения исходных слов: George W.M.D. Bush, Clinton AR, Generation O, President and CEO of BIJ, Inc., Q2K, G.O.P., GOOMBY, NIMBY, NOPE, NOTE, NUMBY, SUV Democrat, RINO, TINO, YIMBY, WMDs u $\partial p$. Несмотря на то, что аббревиация ведёт к экономии и рационализации языка, она вызывает проблемы с расшифровкой особенно новых лексических единиц.

Заимствование - процесс усвоения одним языком слова, выражения или значения другого языка: Tripartisanship, Kalashnikov culture, “Obama Akbar!”, Obama Angst, condo commando, acquis communautair, pizza parliament, Stephanopouli, Baatankwad (Baat - "Hindi for talk" + Aatankwad - "Hindi for terrorism”). Для правильного понимания и грамматического употребления заимствований важную роль играют наличие базовых знаний о языке-доноре, а также контекст.

В результате проведенного нами структурного анализа политической лексики английского языка было установлено, что наиболее продуктивными способами образования неологизмов являются: словосложение, сокращение, суффиксация, аббревиация, заимствование.

По своей природе «неологизмы» не статические, а процессуальнодинамические явления. Обогащая и расширяя язык, они также представляют и трудности при переводе, пока не окажутся на стадии лексикографической интеграции в состав языка. Однако современные электронные словари неологизмов позволяют оперативно получить актуальные данные семантического, грамматического, фонетического характера, тем самым отражая современную языковую картину мира. 


\section{Литература}

1. Белка, Ю.В. Неологизмы английского языка 2013-2014 года // НаукаRASTUDENT.RU. - 2014. - No. 5(05-2014) / [Электронный ресурс] Режим доступа. - URL: http://nauka-rastudent.ru/5/1453/

2. ЛЭС - Ярцева, В.Н. (главред) Большой энциклопедический словарь / В.Н. Ярцева // Языкознание - М.: Большая Российская энциклопедия, 1998. $687 \mathrm{c}$.

3. Unwords.com

4. http://www.urbandictionary.com

5. http://www.wordspy.com 